\section{Wellcome Trust announces spending bonanza}

The Wellcome Trust, the world's largest medical research charity, is planning to boost its annual spending.

The trust, which backs a broad range of biomedical research, will increase its expenditure by $60 \%$ to $£ 4$ billion (US\$8 billion) over the next five years.

Total grant funding is expected to rise from $£ 520$ million to $£ 650$ million annually, according to spokesman Craig Brierley. A portion of the new money will go towards research into the genetic basis for common diseases such as cancer and diabetes.

Some $\mathfrak{E 5 0 0}$ million will go towards assisting construction of a new biomedical campus in London, a fund to develop new treatments based on fundamental science, and a campaign to improve Africa's biomedical infrastructure.

\section{Lab workers exposed to brucellosis by safety tests}

More than 900 people working in 254 labs around the United States and Canada might have been exposed to modified Brucella abortus last autumn, because of their failure

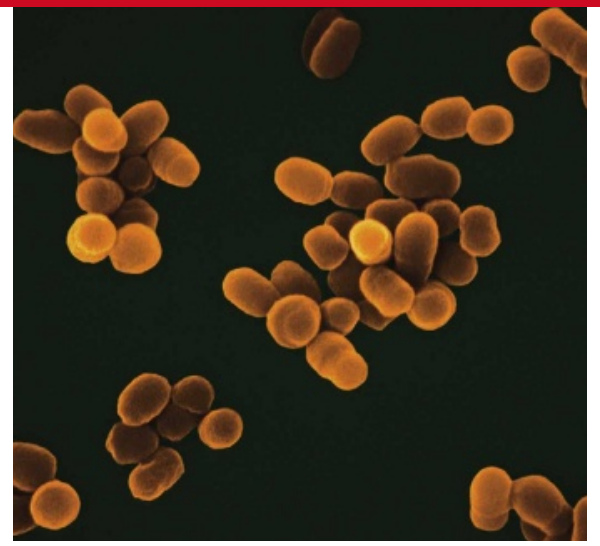

Handle with care: Brucella abortus.

to follow proper handling procedures for the bacterium, the Atlanta JournalConstitution has reported.

Brucella abortus primarily causes disease in cows, but it can also make people ill. It was posted to 1,316 clinical laboratories in a joint exercise - led by the College of American Pathologists, the Centers for Disease Control and Prevention, and the Association of Public Health Laboratories - to test the labs' procedures for dealing with suspected bioterrorism agents.

Also last week, watchdog groups reacted with outrage to news that virologist Yoshihiro Kawaoka is working with a modified Ebola virus in a biosafety level-2
(BSL-2) laboratory at the University of Wisconsin in Madison, but has not consulted the US National Institutes of Health (NIH) about the work. The NIH previously overruled a decision by the university to allow Kawaoka to work with Ebola genes in a BSL-3 lab, saying that it wanted him in a BSL-4 one.

\section{No conflict of interest in misconduct case, says lab}

Officials at the US Department of Energy's Office of Science are resisting a finding by department attorneys that a report of an investigation into alleged scientific misconduct at a national laboratory qualifies for public release, according to a 15 January letter from the department.

The report reviews allegations against electron-microscopy researchers in the group of Stephen Pennycook at Oak Ridge National Laboratory in Tennessee (see Nature 450, 590; 2007). One of the report's three authors, David Williams of the University of Alabama in Huntsville, says investigators spent hours reading papers received from Oak Ridge management, and found mistakes but no misconduct.

Williams also confirms that, prior to the investigation, he and co-editor Barry 
Carter of the University of Connecticut in Storrs had invited Pennycook to contribute a chapter to a future reference book on electron microscopy, with a possibility to share royalties. Williams did not declare the interaction. Oak Ridge claims that when it found out - well after the investigation had been completed - its lawyer said that there was no conflict of interest.

\section{Web alliance speeds up communication with Africa}

African researchers have just been connected by a high-speed Internet link to Europe's research network, GÉANT2. The deal has been struck between GÉANT2 and UbuntuNet, an alliance of African national research networks created in 2005 . It will speed up communications and data transfer not only between African scientists and the estimated 30 million GÉANT2 users in 34 European countries, but also with scientists worldwide - through GÉANT2's connections with the United States and other research networks around the world.

UbuntuNet is not related to Ubuntu, the popular free version of the Linux operating system. But both namesakes help bring affordable quality information technology to African scientists.

\section{Review article retracted amid plagiarism claims}

A review article written by a rheumatologist at Harvard Medical School in Boston, Massachusetts, has been retracted after the journal, Best Practice \& Research Clinical Rheumatology, learned that more than half of the paper may have been plagiarized.

The 2004 article, by Lee Simon (Best

Pract. Res. Clin. Rheumatol. 18, 507-538;
2004), was manually checked after surfacing in an automated trawl through 7 million biomedical abstracts for possible plagiarism (see Nature 451, 397-399; 2008). The retraction was announced on 29 January.

Harvard Medical School has formed a committee to review the matter but has not launched an official investigation, says spokesman David Cameron. Simon declined to comment, saying only: "I'm very sorry that I've been so targeted for something like a review article."

\section{Probe catches glimpse of surface troughs on Mercury}

Down on the floor of the immense Caloris Basin - an impact crater at least 1,300 kilometres wide that scars the surface of the planet Mercury

- lies a set of radial troughs nicknamed 'the spider' (right). This image is one of many sent back by NASA's MESSENGER spacecraft during its 14 January flyby, the first of three planned before it settles into orbit around Mercury in 2011. Project scientists think the troughs in

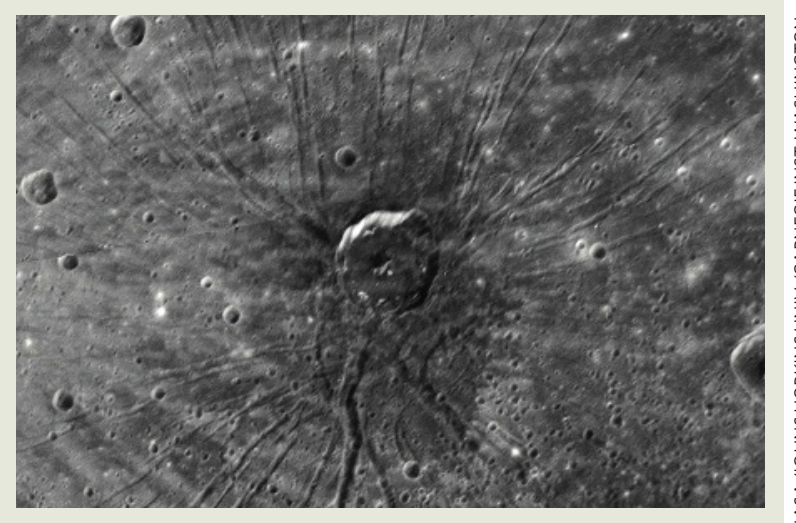

the spider formed as material in the floor of the Caloris Basin pulled apart. A smaller impact crater near the centre may also have contributed to trough formation. 